\title{
Naxos Music Library
}

Im Juli dieses Jahres konnte über den in München ansässigen Fachhandel für digitale Medien Digento die Datenbank Naxos Music Library erworben werden. Die Laufzeit des regulären Abonnements begann am 1. August 2012 und beträgt ein Jahr. Es sind zwei gleichzeitige Zugriffe inklusive Remote Access möglich; erworben wurde die Standardklangqualität mit 64 kbps (AAC-Format). Die Datenbank kann - ebenso wie ein Handbuch zu ihrer Nutzung - über DBIS aufgerufen werden.

Die Naxos Music Library enthält CD-Einspielungen von einigen hundert Musiklabels und mehr als eine Million Tracks von über $70.000 \mathrm{CDs}$. Enthalten sind historische, aber auch Aufnahmen jüngerer Zeit, die jeweils in voller Länge zu hören sind. Vertreten sind neben Werken der klassischen auch Kompositionen der zeitgenössischen Musik, Jazz, Folk, Blues und Gospels, Beispiele für Fado, ebenso Titel aus Pop und Rock, sog. Weltmusik und Entspannungsmusik.

Darüber hinaus gibt es einen Studienbereich, eine Rubrik Quellen und einen Kinderbereich. Hier kann - in englischer Sprache - ein Gang durch die Musikgeschichte unternommen oder der Klang verschiedener Musikinstrumente per Mausklick aufgerufen werden.

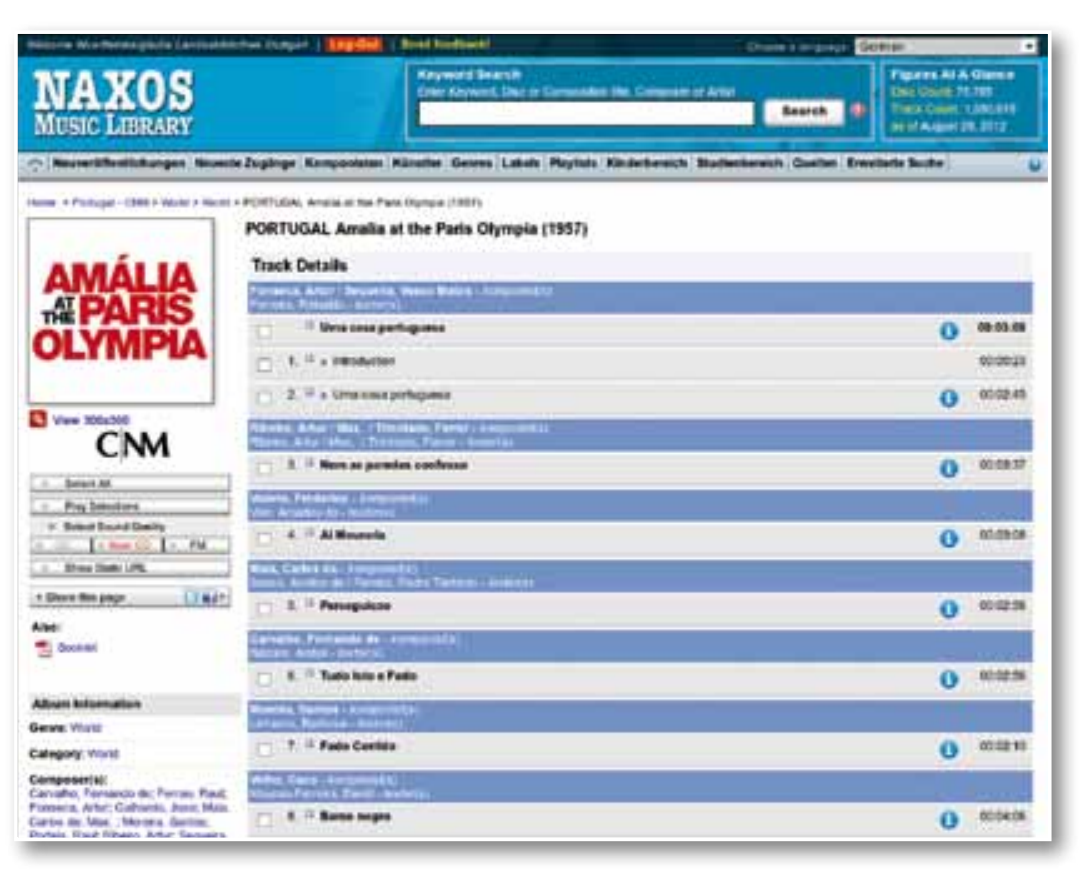

Die Recherche ist entweder über verschiedene Suchmasken möglich (Stichwortsuche und Erweiterte Suche) oder über die Registerkarten Neuveröffentlichungen, Neueste Zugänge, Komponisten, Künstler, Genres und Labels. Bei der Suche ist zu beachten, dass Umlaute nicht aufgelöst einzugeben sind, sondern nur mit dem Stammbuchstaben, d. h. "Zauberflöte" als "Zauberflote", "Händel" als "Handel". Aspekte der Suche und etwa auch das Erstellen von Playlists werden in dem genannten Benutzerhandbuch erläutert.

Ist das gewünschte Album gefunden, so können einzelne der enthaltenen Tracks oder aber alle Titel über den Button Select All im linken Seitenbereich ausgewählt werden. Über Play Selections gelangt man ins Abspielmenü, das sich in einem eigenen Fenster öffnet.

Eine Abbildung des CD-Covers, häufig der Link zum Booklet und Informationen über das jeweilige Album finden sich ebenfalls im linken Bereich der Seite.

Von einer Einspielung des Carnival von Antonin Dvořák, dirigiert von Fritz Busch im Jahre 1950, über einen Mitschnitt von Amalia Rodrigues' Konzert im Pariser Olympia-Theater im Jahr 1957 bis hin zu Architectonics von Erkki-Sven Tüür, gespielt vom Nyyd Ensemble: Die Naxos Music Library hat sowohl für Musikliebhaber und Raritätensammler als auch für Musikwissenschaftler einiges zu bieten.

Ute Becker 